ISSN 0103-7013

Psicol. Argum., Curitiba, v. 29, n. 64, p. 109-119 jan./mar. 2011

Licenciado sob uma Licença Creative Commons

\title{
Sexualidade e deficiência intelectual: Um curso de capacitação para pais ${ }^{1}$
}

\author{
Sexuality and mental retardation: Training course for parents
}

\author{
Paloma Pegolo de Albuquerque
}

Doutoranda do Programa de Pós-Graduação em Psicologia da Universidade Federal de São Carlos (UFSCar), São Carlos, SP Brasil, e-mail: palomanier@yahoo.com.br

\begin{abstract}
Resumo
A literatura aponta que a educação sexual de jovens com deficiência intelectual suscita diversas dificuldades entre as famílias, pois muitas não estão preparadas para lidar com essa questão. Diante dessa necessidade, o objetivo deste estudo foi planejar, aplicar e avaliar um programa de intervenção (curso) para nove pais de jovens com deficiência intelectual de uma escola especial de uma cidade do interior de São Paulo. O curso durou dois meses, tendo oito encontros semanais, e teve caráter teórico e prático, com discussões, dinâmicas de grupo, atividades de role-playing, atividades de resolução de problemas e filmes. Por meio de uma avaliação sobre o curso, e também por meio de entrevistas, perceberam-se alguns ganhos advindos do curso, como aprendizado de conteúdos, troca de experiências e ajuda no cotidiano doméstico. Foram notadas também algumas mudanças, como quebra de preconceitos e alteração nas interações pais/filhos, além de revisão de sua postura como educadores sexuais.
\end{abstract}

Palavras-chave: Sexualidade. Educação sexual. Cursos de capacitação. Relações familiares. Pessoas com deficiência mental.

\begin{abstract}
Literature points sexual education of mentally disabled youngsters as a source of difficulties for families, once many of them aren't ready to deal with that matter. Considering that, the goal of this study was to design, apply and assess an intervening program (course) on nine parents of mentally disabled youngsters from a special school at a city in São Paulo state. The course lasted two months, in which time eight weekly meetings, of theoretical and practical character, with discussions, group dynamics, role-playing and problem-solving activities, and films exhibitions,
\end{abstract}

1 Este trabalho teve apoio da Fundação de Amparo à Pesquisa do Estado de São Paulo (Fapesp). 
were held. By means of an assessment of the course and the interviews, we could notice some gain resulting from the course, like contents learning, exchange of experiences and help in the domestic routine. We could notice also some shift, such as breaking of prejudices and alterations in the parents-children interactions, as well as a revision of their attitude as sexual educators.

Keywords: Sexuality. Sex education. Training courses. Family relations. Mentally disabled persons.

\section{Introduçáo}

A sexualidade refere-se a um conjunto de comportamentos complexos que envolvem a busca da satisfação pessoal, indo além dos aspectos biológicos e genitais. Trata-se de algo essencial para o desenvolvimento integral do ser humano (Bastos \& Deslandes, 2005), importante inclusive na construção da identidade. Pode-se entender, portanto, sexualidade como amor, afetividade, busca de prazer e também genitalidade, como afirmam Maia e Aranha (2005); e deve-se situá-la sempre no contexto do relacionamento, do prazer e da responsabilidade (Glat \& Freitas, 2002).

De acordo com França Ribeiro (2000), a educação sexual é o processo pelo qual uma pessoa aprende sobre sexualidade ao longo da vida. Para Werebe (1998), a ação educativa da família em relação à sexualidade é a mais importante, pois envolve a formação de opiniões, atitudes e comportamentos do jovem. Essa ação é informal e os pais geralmente não se dão conta de que já estão educando, uma vez que transmitem ensinamentos mais pelo que fazem do que pelo que dizem.

Schiavo (2004) também pontua que apesar de os pais serem os principais educadores sexuais dos filhos, pois são os primeiros modelos de homem e de mulher com os quais a criança interage, sabe-se que muitos ainda experimentam dificuldades para abordar a temática sexual entre eles mesmos e mais ainda com seus filhos. Muitos advieram de modelos educacionais rígidos e repressores, sentindo-se constrangidos e inseguros para esse tipo de diálogo com os jovens. Dessa forma, é comum que as famílias não tenham preparo para lidar com a questão da sexualidade e encontrem dificuldade para orientar os filhos. Se a questão sexual geralmente é controvertida e delicada de ser abordada na sociedade, o que se esperar quando se trata da sexualidade das pessoas com deficiência intelectual? Segundo Plunkett, Staceylee, Neal e Sanchez (2002), a população geral tem atitudes variadas sobre o assunto sexualidade humana, mas quando se fala de indivíduos com deficiência intelectual, os preconceitos e problemas costumam ser intensificados.

Sobre os jovens com deficiência intelectual, Glat e Freitas (2002) afirmam que a sexualidade geralmente é percebida pelos pais e professores dessas pessoas como algo biologizado, genitalizado e destituído de prazer. Juntando-se a essa dificuldade, há as inabilidades de os pais lidarem com a própria sexualidade; e o que é pior, há a dificuldade de lidar com o fato de ter gerado um filho imperfeito. Somam-se, então, muitas dificuldades e o resultado da relação sexualidade/deficiência intelectual pode não ser positivo.

De acordo com os estudos de Giami (2004), a percepção de muitas famílias e profissionais sobre a sexualidade de seus filhos/alunos se alterna: por um lado, eles são considerados sexualmente infantis e assexuados e, por outro, sexualmente agressivos e sem controle. $\mathrm{O}$ estereótipo do deficiente como sexualmente agressivo ou assexuado é uma extensão da visão popular do deficiente como um ser "demoníaco" ou "eterna criança". O autor ainda coloca que tanto em pais como em educadores, apesar das diferentes crenças, há um fundamento único que é a negação da sexualidade.

De acordo com Gherpelli (1995), há pais que não reconhecem o desenvolvimento dos filhos e se assustam quando percebem seus interesses afetivos e sexuais. Chegam a se surpreender quando, depois de ignorar a sexualidade dos filhos e não lhes dar orientação, observam manifestações sexuais consideradas por eles inadequadas (Glat \& Freitas, 2002). Atribuem isso à deficiência e não à educação sexual omissa ou à falta de educação nesse âmbito. Ballan (2001) também aponta que pais de crianças com deficiência tendem a ter dúvidas sobre o manejo apropriado do desenvolvimento da sexualidade dos filhos. Estão confusos, ansiosos e têm atitudes ambivalentes acerca dessa questão, pois, apesar de 
considerarem os direitos dos filhos com relação à sexualidade, na realidade não os preparam para isso.

$\mathrm{Na}$ tentativa de "proteger" os filhos dos "perigos do mundo", muitos pais os escondem em casa eimpedem qualquer troca social que eles venham a realizar com a sociedade em geral. Sampaio (1995) realizou uma pesquisa com mães de jovens com deficiência intelectual tendo como objetivo caracterizar a percepção delas sobre a sexualidade dos filhos e percebeu que essas mães tendem a limitar, tanto por insegurança, desconhecimento ou superproteção, as interações dos filhos com outras pessoas; além disso, não promovem situações facilitadoras para que seus filhos possam criar vínculos de amizade. Segundo Assumpção Jr. e Sprovieri (2005), muitas vezes as famílias mantêm os filhos com deficiência em eterna dependência funcional.

Medo de gestações indesejadas, medo de que os filhos não expressem a sexualidade da forma considerada por eles como apropriada, medo do contágio de doenças sexualmente transmissíveis, medo que sejam vítimas da exploração sexual ou situações embaraçosas e perigosas são realidades comuns a esses pais. Todas essas preocupações levam à superproteção, privando crianças com deficiência de seus direitos e de sua liberdade e falham em equipá-las com o conhecimento para lidar apropriadamente com experiências sexuais que encontrarão (Ballan, 2001).

De acordo com Glat, Nunes, Ferreira e Mendes (1998), o baixo nível de expectativa e a superproteção que as famílias de pessoas com deficiência intelectual exibem é um dos maiores entraves para o desenvolvimento das potencialidades desses indivíduos. E a falta de discussões esclarecedoras sobre sexualidade da pessoa com deficiência intelectual com a família e os amigos pode se converter em mensagens negativas acerca da própria sexualidade (McCabe, 2001).

A superproteção é uma forma de repressão sexual que causa danos, às vezes irreparáveis, ao desenvolvimento psicológico e social do indivíduo. Muitos pais acreditam que sempre estarão por perto para proteger os filhos. Segundo Glat (2005), essa suposta onipotência dos pais é uma ilusão que pode aliviar a tensão temporariamente, mas acaba impedindo o pleno desenvolvimento dos filhos. Essa postura dos pais amplia a exposição e a vulnerabilidade dos jovens diante de situações perigosas, já que eles não aprendem a lidar com a sexualidade e com os riscos.
Pueschel e Scola (1988) realizaram uma pesquisa com 73 pais de adolescentes com síndrome de Down, com o objetivo de levantar informações acerca das percepções dos pais em relação à sexualidade de seus filhos. Como resultado principal encontraram que a maioria dos pais não se sentia confortável falando com seus filhos sobre assuntos relacionados à sexualidade e tinha dificuldades com o tema.

Em sua pesquisa com famílias de pessoas com deficiência intelectual, Glat (2005) relatou que, de modo geral, os pais têm dificuldade para orientar os filhos, mesmo admitindo que seja necessário. Confirmando estudos anteriores dessa mesma autora, percebeu-se que a orientação sexual, quando é dada, resume-se a informações fisiológicas, ignorando-se a libido e o prazer.

Muitos pais de pessoas com deficiência intelectual não percebem as necessidades sexuais dos filhos. Em geral, eles focam nas expressões sexuais inadequadas e no medo da exploração sexual, no receio de que pessoas mal intencionadas se aproveitem da "ingenuidade" dos seus filhos. Há também o medo de que a inocência dos filhos acabe, o que leva muitos pais a não querer que eles recebam orientação sexual (Glat, 2005).

Alguns pais, de acordo com Assumpção Jr. e Sprovieri (2005), evitam abordar o assunto com medo de aflorar a sexualidade dos filhos. Segundo Giami (2004), os pais de jovens com deficiência intelectual acreditam que o meio que cerca seus filhos é sempre mais sexualizado que seus próprios filhos; dessa forma, seriam sempre os outros que viriam "provocar" a sexualidade de suas "crianças".

Giulio (2003) afirma que os pais e cuidadores de pessoas com deficiência devem equipar-se com o conhecimento necessário e as habilidades para prover educação e orientação sexual apropriada para essas pessoas. Segundo Ballan (2001), os pais necessitam de orientação e suporte de educadores sexuais para obter um entendimento claro da sexualidade de seus filhos. Para ajudar os pais em seu papel como educadores sexuais, profissionais podem desbancar ideias errôneas sobre sexualidade e deficiência, prover informações sobre o desenvolvimento sexual das crianças e propor estratégias para promover comportamentos apropriados por meio da orientação sexual.

Luengo et al. (2000) desenvolveram uma intervenção por meio de oficinas com jovens 
portadores de deficiência intelectual e com suas mães durante oito semanas, em que trabalharam temas como adolescência, afetividade, sexualidade, anatomia e fisiologia da reprodução, amizade, amor, paternidade responsável e autoestima. Eles perceberam que o nível de autoestima dos jovens e os conhecimentos adquiridos em reprodução e sexualidade aumentaram, bem como existiu um aumento nos conhecimentos das mães.

Maia (2006) relatou uma pesquisa realizada na qual ela investigou os relatos sobre a sexualidade de pais e de jovens com deficiência intelectual em construir estratégias e depois implementar uma proposta de orientação sexual; foram formados dois grupos de jovens e um de pais, nos quais se discutiu temas a partir do interesse dos participantes. Ela descreveu que os resultados dessa intervenção foram válidos, pois se tentou tornar os pais mais conscientes e preparados para lidar com a sexualidade dos filhos. No entanto, existiram algumas limitações, como uma dificuldade em aprofundar os temas abordados na intervenção, e não houve avaliação do entendimento e da apreensão de temas complexos pelos participantes.

Já Amaral (2004) realizou uma pesquisa com oito pais e responsáveis por jovens com deficiência intelectual, divididos em dois grupos de duas instituições de ensino especial. Ela fez uma entrevista inicial para levantamento das necessidades e interesses e para caracterização dos repertórios conceitual e de condutas dos participantes, depois realizou um programa de orientação sexual composto de cinco encontros com cada um dos dois grupos e, por fim, realizou entrevistas finais para avaliação do programa e para caracterização dos repertórios conceitual e de condutas dos participantes após a aplicação da pesquisa. Apesar das limitações, a autora relatou ser possível afirmar que o programa de orientação sexual é uma ferramenta relevante para a finalidade proposta, já que após o programa a maior parte dos participantes passou a apresentar indicações de aceitação e reconhecimento do direito do filho com deficiência intelectual exercer sua sexualidade, apesar de muitos ainda continuarem reprimindo a sexualidade deles. Os dados indicaram que, a partir do programa, foi possível produzir alterações no repertório conceitual e de condutas de pais em termos de indicações verbais dadas por eles, passando de desfavoráveis para favoráveis em relação a diferentes aspectos e todos os participantes apresentando pelo menos uma mudança.

Amaral (2004) sugere também que novos trabalhos observem condições de ensino capazes de promover aprendizagem e mudança comportamental em todos os participantes de forma mais completa e abrangente. No mesmo sentido, Aunos e Feldman (2002) também recomendam novos estudos comparando atitudes entre diferentes grupos envolvidos com pessoas com deficiência mental, como pais, professores e profissionais, e examinando o impacto de preconceitos na expressão sexual dessas pessoas.

Diante dessas necessidades apontadas pela literatura e pela vivência da própria pesquisadora, julgou-se importante a realização de um programa de intervenção relacionado ao tema, buscando-se a capacitação de pais e responsáveis por jovens com deficiência intelectual por meio do maior preparo e formação para lidar com os filhos, incentivando, assim, o desenvolvimento global desses indivíduos. O objetivo desse trabalho foi, portanto, planejar, aplicar e avaliar um programa de intervenção sobre educação e orientação sexual (curso) para pais de jovens com deficiência intelectual.

\section{Método}

Participaram do curso Sexualidade e Deficiência Intelectual nove pais ou responsáveis por jovens com deficiência intelectual. A maioria era composta por mães, havendo três pais, uma avó e seu companheiro; a idade média dos participantes era de 57 anos. Em relação à escolaridade, a maioria possuía ensino fundamental incompleto e pertencia à classe $\mathrm{C}$, de acordo com o Critério Brasil. ${ }^{2}$ Já no que se refere aos filhos, as idades variaram entre 12 e 32 anos, com média de 20,8 anos, a maioria era do sexo feminino e apresentava deficiência intelectual leve, de acordo com o prontuário da escola. É importante esclarecer que todos esses participantes moravam com os jovens com deficiência intelectual.

O estudo foi realizado numa escola especial de uma cidade de porte médio do interior de São Paulo. A escola atende pessoas com deficiência intelectual e outros tipos de deficiências relacionadas

2 Tais informações foram retiradas de: www.ibope.com.br 
e possui no período 482 alunos e 65 professores. Foram utilizadas duas salas de tamanho médio do setor técnico da escola para realização da maioria das entrevistas e um auditório para a realização do curso. Apenas algumas entrevistas foram realizadas nas próprias residências dos participantes. É importante apontar que todos os cuidados éticos foram tomados e este trabalho foi aprovado pelo Conselho de Ética em Pesquisa da Universidade.

Inicialmente foram realizadas entrevistas com os pais utilizando-se um roteiro de entrevista elaborado pela própria pesquisadora com base na literatura. Os temas abordados referiram-se às atitudes em relação ao tema da sexualidade - tais como necessidades/desejos sexuais de pessoas com deficiência intelectual, namoro, casamento e paternidade/ maternidade - e à forma de lidar com a educação e orientação sexual dos filhos, como conversa sobre sexualidade, dificuldades e problemas relacionados à sexualidade, informações dadas, educação/orientação sexual e papel na educação sexual. Utilizou-se também um Termo de Consentimento Livre e Esclarecido.
Todas as entrevistas foram gravadas e posteriormente transcritas pela pesquisadora. Partiu-se das principais carências e dificuldades dos entrevistados para a montagem do curso e estabelecimento de suas prioridades.

O curso foi realizado por meio de encontros semanais com duração de duas horas cada um, resultando em oito encontros (16 horas de duração, dois meses ao todo). Foram realizadas pela pesquisadora exposições teóricas todos os dias, exceto nos dois últimos, destinados à apresentação de filmes e às dúvidas e aos esclarecimentos. Para tanto, foram utilizados um retroprojetor e transparências, com o objetivo de tornar a exposição mais atraente e organizada. Houve também momentos para se trabalhar as dificuldades e necessidades relatadas pelos participantes, por meio de discussões, dinâmicas, atividades de role-playing, atividades de resolução de problemas, filmes e outras.

A Tabela 1 apresenta as principais características do curso, tais como os temas, objetivos e principais atividades desenvolvidas.

Tabela 1 - Descrição dos encontros do curso Sexualidade e Deficiência Intelectual

(Continua)

\section{Tema}

Objetivos

1 - O que é sexualidade?

2 - Sexualidade e deficiência intelectual

3 - O papel da família, da escola e da sociedade diante da sexualidade de pessoas com deficiência intelectual

4 - Educação e orientação sexual de pessoas com deficiência intelectual e social dessa questão. circundam a questão. sexuais das pessoas.

\section{Descrição geral das atividades}

Contrato de sigilo; dinâmica de apresentação dos participantes; exercício de reflexão no qual foi pedido que os participantes falassem sobre a educação sexual que receberam quando eram adolescentes; entrega de um diário para que os pais anotassem, em casa, os comportamentos dos filhos relacionados à sexualidade e sua reação perante eles. cionamento entre os seres humanos; abordar a sexualidade como um aspecto natural e positivo da vida; e dar uma visão histórica

Discutir o conceito de deficiência intelectual; discutir a sexualidade na deficiência intelectual; desmistificar alguns mitos que

Explicitar os papéis da escola, da família e da sociedade no processo de educação/ orientação sexual das pessoas com deficiência intelectual; dar parâmetros de como se comportar em situações diversas relacionadas à tomada de decisões na educação dos filhos; refletir sobre a influência das agências sociais sobre o comportamento e as atitudes

Discutir a importância da educação e orientação sexual para as pessoas com deficiência intelectual; apresentar propostas de conteúdo de programas de orientação sexual.
Dinâmica dos medos no papel: os participantes escreviam seus medos, anseios e preocupações acerca da sexualidade de pessoas com deficiência intelectual; depois cada um sorteava um papel e lia em voz alta, relatando como se sentiam em relação ao conteúdo.

Atividade de role-playing: os participantes deveriam encenar uma situação envolvendo pais e filhos, relacionada ao tema da sexualidade.

Dinâmica das histórias: os participantes escreviam o início de uma história sobre a sexualidade na deficiência intelectual até que a pesquisadora pedisse para que trocassem os papéis e dessem continuidade à história de outra pessoa. No final, as histórias eram lidas e comentadas. 
Tabela 1 - Descrição dos encontros do curso Sexualidade e Deficiência Intelectual

(Conclusão)

5 - Comportamentos sexuais considerados inadequados

6 - Relacionamentos amorosos de pessoas com deficiência intelectual

7 - Relacionamentos amorosos de pessoas com deficiência intelectual II ciência intelectual: revisão, dúvidas e encerramento
Citar os principais comportamentos sexuais considerados inadequados; debater a funcionalidade desses comportamentos; dar exemplos de como lidar com eles; levar os participantes a refletir sobre como podem agir diante dessas situações.

Refletir sobre os prós e contras dos relacionamentos amorosos de pessoas com deficiência intelectual; dar parâmetros de comportamento de como os participantes podem agir diante de situações novas com os filhos/alunos.

Aprofundar a discussão sobre os relacionamentos amorosos de pessoas com deficiência intelectual, revisando outros aspectos tratados no curso; exemplificar, por meio de recursos audiovisuais (televisão, aparelho de DVD, filmes), situações relacionadas ao tema.

Avaliar os conhecimentos adquiridos pelos participantes no curso; debater e tirar dúvidas ainda existentes; refletir sobre os principais aspectos tratados durante o curso.
Atividade de reflexão sobre um exemplo de comportamento sexual inadequado, solicitando-se que os participantes respondessem a questões sobre uma situação descrita; sendo a atividade retomada e discutida após a explanação teórica da pesquisadora.

Dinâmica das opiniões opostas: os participantes foram divididos em dois grupos e foram apresentadas duas situações (casamento e paternidade de pessoas com deficiência intelectual), solicitando-se que cada grupo assumisse a postura de ser favorável a uma das situações e contra a outra. Eles deveriam escrever três argumentos e tentar convencer os integrantes do outro grupo, seguindo-se um debate.

Apresentação de recortes de dois filmes sobre namoro, casamento e paternidade de pessoas com deficiência intelectual; discussão sobre os filmes.

Avaliação sobre o curso e revisão de todo o conteúdo do curso.

Fonte: Dados da pesquisa.

Em todos os encontros foram entregues também resumos de uma página com as informações principais discutidas na semana anterior, para atualizar aqueles que não haviam comparecido $\mathrm{e}$ também servir como revisão, formando-se uma cartilha sobre sexualidade e deficiência intelectual no final do curso. Foram distribuídos ainda pequenos textos e informes de uma página sobre diversos temas, como: deficiência intelectual; sexualidade; sexualidade na deficiência intelectual; influência da mídia sobre a sexualidade; pais e a sexualidade; superproteção; escola; adolescência; limites; masturbação; e aspectos biológicos da reprodução.

Foram sorteados e entregues brindes no final de cada encontro, com o objetivo de incentivar a participação dos presentes. Os brindes foram basicamente livrinhos infantis de uma coleção sobre sexualidade. Ao final de todos os encontros ocorria sempre um momento de confraternização, com o oferecimento de bebidas e comidas aos presentes.

Após três meses do final da intervenção, foram feitas entrevistas com cada um dos participantes - na própria escola ou nas casas deles -, utilizando-se o mesmo roteiro anterior. As entrevistas foram gravadas e transcritas para análise. Os dados obtidos foram ordenados e agrupados conforme núcleos de sentido comuns e transformados em categorias de análise, seguindo-se a técnica de análise de conteúdos de Bardin (1977). Foram realizadas, então, análises qualitativas por meio da percepção da pesquisadora sobre as etapas da pesquisa e principalmente da discussão com a literatura. Além disso, foi analisado também um questionário de avaliação sobre o curso, entregue no último dia aos participantes, que continha seis questões abertas para que eles expressassem suas opiniões, críticas e sugestões relacionadas ao curso.

\section{Resultados}

\section{Principais efeitos da intervençáo}

Muitos pais relataram terem gostado do curso, como demonstra a verbalização seguinte: "estou muito feliz. de colaborar com você, porque eu estou te ajudando e você me ajudou muito, o teu trabalho, então, eu acho que 
foi muito bom" (P13). Foram citados diversos aspectos positivos em relação ao curso, como o aprendizado de novos conhecimentos e esclarecimento de dúvidas: "ajuda a gente a orientar, porque tem coisa que a gente não sabia, aprendemos com você" (P9) e "eu não sabia dessas coisas e acabei sabendo [...]. Tem pessoas que têm filhos assim e nem sabem o que fazer, e com uma orientação a pessoa vai aprendendo" (P2).

Os participantes apontaram também uma troca de experiências e ideias, como ilustram as verbalizações seguintes: "eu acho bom mesmo cada um falar dos seus problemas, vocêpoder ver o que o outro passa; teve mãe no curso que en vi que passa problemas piores do que o meu?' (P4); "teve a mãe falando do filho; eu achava que só eu tinha dificuldade, vergonha de certas coisas" (P6); e "ali a gente está conhecendo outras pessoas, está tendo relacionamento com outras pessoas, a gente sabe que o problema não é só da gente. E com isso, com exemplos, a gente aprende a estar lidando" (P7).

Tanto nas entrevistas pós-intervenção como nos questionários de avaliação do curso, foram apresentados diversos aspectos que podem sugerir mudanças, como uma mudança de visão sobre a sexualidade e da forma de lidar com ela.

Mudou quase tudo, passei a encarar com naturalidade, pois quando me deparei com certas cenas não sabia o que fazer, hoje já sei como encarar e me relacionar com o problema [...], eu consigo encarar isso daí com mais naturalidade, porque a gente vê que é uma coisa normal! (P1).

Agora eu estou tendo liberdade com as meninas para falar sobre esse assunto, mas antes eu não tinha não, antes eu era mais fechada! [...] Essa orientação que foi passada para a gente lá também não serviu só para a gente lidar com ela, serviu também para lidar com as outras filhas! (P1).

O curso mudou eu, como en encarar, ver a situação dela, namorar, essas coisas assim. Mudou muito a minha cabeça! (P2).

Poderia ter aprendido isso tudo muito antes, não teria sofrido tanto! Sofri muito, mas graşas a Deus agora abriu a minha mente! (P1).

Houve quebra de tabus e diminuição do medo e da timidez em tratar o tema da sexualidade, fatores também apontados por P1: "certos tabus de quando a gente era criança que nos ensinaram foram desfeitos epude aprender que a sexualidade emportadores de deficiência é normal, deve ser tratado com carinho".

No que concerne ao diálogo sobre sexualidade com os filhos, ocorreram mudanças de opinião de alguns pais, como P1, que antes do curso relatava ter dificuldade para falar sobre sexo e depois afirmou ter passado a falar normalmente, como demonstram os dois momentos a seguir:

tem mães que têm um certo tabu, um certo receio de falar sobre isto; eu mesmo sou assim [...] tem hora que eu dou uma freada, eu não tenho muito jeito para falar sobre isso! Eu deixei muito a desejar com as minhas filhas! (P1).

Estou com a mente mais aberta! Já converso com ela mais abertamente (P1).

As entrevistadas P1 e P8 tinham afirmado também nas entrevistas pré-intervenção que suas filhas não possuíam informações sobre sexualidade e, nas entrevistas pós-intervenção, passaram a relatar que elas tinham, pois começaram a conversar bastante com as jovens, como aponta P8: "eu gostei porque teve a possibilidade de conversar mais com ela; essas coisas que a gente ficava meio assim para conversar, a gente passon a conversar com ela".

Sobre o Diário de Comportamentos dos Filhos, distribuído no primeiro dia do curso, P1 fez diversas anotações relevantes. Na primeira, ela relatou que perguntou para a filha se esta possuía alguma dúvida sobre sexualidade e a filha fez uma pergunta, mas ela não respondeu, pois havia chegado visita. No segundo dia, afirmou que havia dado um livro sobre sexualidade para a filha ver e ofereceu-se para tirar dúvidas, mas como ela mesma apontou: "não tive coragem de ler o livro pra ela" (P1). No terceiro dia, a situação se repetiu e ela escreveu: "fiquei sem saber o que falar" (P1). Já no último dia ela fez a seguinte consideração:

cheguei da reunião (curso), fui até o quarto e peguei o livro. Expliquei como isso acontece, que ela pode se tocar e beijar o travesseiro como muitas vezes ela faz. (P1).

Ai começou a perguntar, quando cheguei na figura do ato sexual [...] perguntou se quando se namora,

3 Os participantes serão identificados com a letra P seguida de números para impedir sua identificação. 
conhece, já vai para a cama. Expliquei que não, que tem que se conbecer melhor e se prevenir para não contrair doenças $(\mathrm{P} 1)$.

Entretanto, ainda foram citadas muitas dificuldades por alguns pais para conversar sobre sexualidade com os filhos. Continuaram sendo apresentados diversos motivos para a ausência de conversa, como demonstra P7: "na realidade eu nem converso, não dá tempo".

Acerca da visualização de um papel na educação e da orientação sexual dos filhos com deficiência intelectual, notaram-se muitas verbalizações relacionadas.

Eu acho que tem que conversar com ela da mesma forma como você conversa com uma criança normal, porque educação sexual é uma coisa que você fala com o que tem deficiência e com o que não tem. Então tem que conversar sobre sexualidade com ela, porque senão ela vai aprender de outra forma (P1).

Tem que explicar também para não acontecer também de muitos querer se aproveitar (P8).

Os participantes citaram diversos papéis na educação e na orientação sexual de seus filhos, como demonstram P7 e P9: "o papel da familia tem que ter. Se ela perguntar as coisas não pode falar: "aí não sei" "(P1); "a gente tem sempre que explicar as coisas antes, tem que explicar tudo para eles; é o papel da gente fazer isso" (P9).

Também foram percebidas muitas reflexões em relação ao local em que a sexualidade deve/ pode ser discutida/trabalhada: "na hora que surge a oportunidade, seja no local que for, você deve trabalhar o correto. Porque se não é discutido, a televisão, o amigo já fala, pode fazer coisa errada" (P7). Alguns deram a entender que passaram a considerar a importância da família nesse processo: "tudo começa de casa, se a criança já vai bem orientada de casa tudo é mais fácil!" (P9).

\section{Discussáo}

As verbalizações indicam o aumento da percepção dos participantes acerca dos interesses afetivo-sexuais por parte dos filhos, pois alguns pais que antes não os percebiam passaram a fazê-lo. De forma semelhante, Amaral (2004) percebeu que a maior parte dos pais participantes de seu programa de orientação sexual passou a apresentar indicações de aceitação e reconhecimento do direito do filho com deficiência intelectual exercer sua sexualidade.

E o mais importante, a forma como esses desejos, necessidades e interesses foram considerados é que parece ter mudado, pois eles passaram a ser encarados com mais naturalidade, como algo que faz parte da vida de qualquer jovem. Diversos autores, como Ballan, (2001), Glat (2005), Giulio, 2003, Bastos e Deslandes (2005) e Maia (2006) já afirmavam que não há diferença significativa entre os desejos e interesses sexuais de pessoas com deficiências e sem deficiência.

Pode ser que a dificuldade dos pais para conversar com os filhos sobre sexualidade, mesmo após a realização do curso, esteja ligada ao fato de que com o curso muitos deles tentaram realizar essa aproximação e perceberam tais dificuldades, algo que não havia ocorrido com tanta frequência antes. De qualquer modo, a dificuldade apresentada pelos pais está de acordo com a pesquisa que Pueschel e Scola (1988) realizaram com pais de adolescentes com síndrome de Down e como resultado principal foi encontrado que a maioria não se sentia confortável falando com seus filhos sobre assuntos relacionados à sexualidade e tinham dificuldades com o tema.

Já no que se refere ao papel de educadores sexuais dos filhos, há indícios de que tais pais passaram a reavaliar sua função na educação e orientação sexual dos filhos. Esses são, portanto, indicações de benefícios gerais do curso no dia a dia desses participantes, possibilitando outro caráter às suas experiências de vida relacionadas à sexualidade.

Em relação ao curso algumas reflexões são possíveis. A pesquisadora teve algumas dificuldades talvez por não conseguir simplificar os assuntos a serem trabalhados num nível mais acessível ao entendimento, e principalmente assimilação, dos participantes. Da mesma forma, Maia (2006) descreveu, como limitações de seu trabalho de orientação sexual a pais de jovens com deficiência intelectual, a dificuldade em aprofundar os temas abordados na intervenção e a não avaliação do entendimento e da apreensão de temas complexos pelos participantes.

Outro aspecto difícil foi a ocorrência de faltas e desistências dos participantes durante o curso, o que gerou certa instabilidade no grupo e dificuldade para programação de atividades que exigiam um número mínimo de pessoas para serem bem-sucedidas. Em todos os encontros chamou a 
atenção a reduzida presença de pessoas e a desistência, o que pode indicar algumas hipóteses e reflexões, como o fato deles não considerarem a sexualidade dos filhos algo importante, preferindo ignorá-la e tratando-os como eternas crianças, o que seria mais cômodo, conforme apontam Giami (2004), Glat (2005), Glat e Freitas (2002), Ballan (2001) e Giulio (2003), entre outros.

Além disso, parece haver também uma dificuldade específica de alguns participantes para lidar com o tema da sexualidade, independentemente de estar associado com a questão da deficiência intelectual, o que pode complicar a participação deles em um grupo desse feitio. Isso está de acordo com o que afirma Schiavo (2004) e Werebe (1998) ao tratar das dificuldades comuns dos pais em geral com essa temática.

Também se pode considerar, a partir da reduzida presença, um provável medo dos participantes em estabelecer mudanças em suas formas de educar. Alguns podem preferir continuar agindo do mesmo jeito porque mudar exige sacrifícios, autoanálise e revisão da própria postura.

Cabe enfatizar também que, quando a pesquisadora deixava situações em aberto no grupo dos pais e pedia a participação deles, muitos partiam para discussões não relacionadas ao tema em si; é como se eles quisessem falar apenas de si mesmos, de seus problemas e necessidades. Isso pode indicar também uma carência que eles possuem de espaço para se expressar e talvez grupos para tratar de assuntos dos filhos devam ser precedidos por um que trate dos assuntos dos pais. Da mesma forma, Maia (2006) percebeu, em sua proposta de intervenção relacionada à sexualidade na deficiência intelectual com pais, que, ao contrário do que se pensava, os interesses e as motivações dos pais extrapolaram as questões sobre a sexualidade dos filhos.

Parece ser um problema amplo a falta de interesse em participar de trabalhos desse feitio e aprender mais. Há tantas dificuldades básicas na vida dessas famílias que pode ser que a sexualidade não seja vista como algo prioritário por pais, a ponto de se dedicarem a esse assunto. Dessa forma, seria necessário, então, atentar para a vulnerabilidade social das famílias antes de partir para qualquer trabalho específico em qualquer área.

Essa vulnerabilidade também foi percebida por Sampaio (1995) ao apontar que as mães da sua pesquisa enfrentavam um encadeamento de problemas vivenciados por pessoas que vivem em condições econômicas, sociais e educacionais desprivilegiadas e carentes. Essas mães não estavam preparadas para lidar com a própria sexualidade e, consequentemente, nem com a dos filhos. Glat e Freitas (2002) também afirmam que muitas famílias se eximem da responsabilidade de prestar orientação sexual aos seus filhos seja por ignorância, por questões socioeconômicas e sociais, por dificuldades psicológicas ou mesmo por omissão.

\section{Consideraçóes finais}

De forma geral, as principais indicações de mudanças apresentadas pelo grupo dos pais referiram-se a alterações na forma de enxergar a sexualidade na deficiência intelectual, destacando-se um maior reconhecimento das expressões sexuais e das necessidades das pessoas com deficiência intelectual, bem como uma maior reflexão sobre o tema. Parece ter havido também uma revisão dos participantes quanto à sua posição diante da questão sexualidade / deficiência intelectual, com quebra de tabus, perda da timidez e aumento da visualização de um papel ativo no cotidiano dos filhos. Tudo isso pode se refletir na qualidade das interações relacionadas à educação/orientação sexual dos filhos.

Tais mudanças de opinião indicam uma ampliação das reflexões pelos participantes sobre o tema sexualidade/deficiência intelectual, como, por exemplo, a percepção da importância da sexualidade na vida das pessoas com deficiência intelectual e uma atenção e respeito maior por seus interesses e necessidades afetivo-sexuais. Houve indícios de um aumento da segurança e do preparo para lidar com o tema e um questionamento do seu papel diante desse processo. Esses aspectos reunidos parecem refletir na melhoria da disposição dos pais diante das demandas dos filhos, como foi percebido, por exemplo, pelo aumento de diálogo pai e filho e de perguntas referentes à sexualidade por parte dos jovens.

Entretanto, todas as dificuldades dos pais apresentadas anteriormente, principalmente a dificuldade de preparação dos filhos para uma vivência inclusiva na sociedade no que se refere à sexualidade, levam à consideração de que somente um curso parece pouco para mudar a rotina dos pais, tanto no que se refere a suas opiniões sobre a sexualidade 
na deficiência intelectual quanto às atitudes e, principalmente, comportamentos de orientação sexual. Os pais possuem muitas necessidades próprias e aparentemente apresentam dificuldades em lidar com a própria sexualidade. Como aponta Werebe (1998), a orientação sexual não é uma panaceia e não irá resolver todos os problemas daqueles que a recebem; é sim, um primeiro passo na implantação de mudanças reais e consistentes.

Isso demonstra que o fato de ter dificuldades em falar sobre sexo é algo que não muda só com a participação em um curso, pois este garante principalmente a informação teórica, mas a mudança de comportamento é algo que envolve diversas variáveis, como a educação sexual recebida ao longo da vida e os valores pessoais. Enquanto pessoa, o pai carrega consigo, fruto de sua própria história e educação sexual precária, inseguranças, dúvidas, desconhecimento, tabus e medos. E tudo isso influenciará a facilidade ou não para abordar a questão da sexualidade, a predisposição para imprimir mudanças nos comportamentos de orientação sexual e até a persistência diante das dificuldades desse processo.

Deve-se considerar a questão sob o ponto de vista preventivo e não remediativo, como tem acontecido até então no cenário familiar ao tentar-se evitar que os filhos tomem contato com o tema da sexualidade, vivam segregados das oportunidades de contato amoroso e sexual e assim não apresentem "problemas". A educação sexual deve ter início em casa e continuar na escola. Para isso, precisam ser testadas estratégias de aproximação entre a escola e a família para que, utilizando o aparato dessa instituição, como espaço físico e recursos humanos, possam visualizar melhor sua atuação junto aos filhos, no que se refere à educação sexual. Isso porque, apesar da literatura apontar que os pais são os principais educadores sexuais dos filhos, sabe-se que as limitações impostas pela realidade, como pouco estudo e informações, além do diálogo reduzido entre pais e filhos, leva à não concretização desse papel. E, a partir daí, deve-se pensar em formas alternativas de estimular a participação dos pais no desenvolvimento da sexualidade dos filhos.

Novos estudos voltados ao desenvolvimento de estratégias mais eficazes de envolvimento dos participantes de tais programas são recomendados, tornando aquilo que é aprendido parte do cotidiano deles, facilmente apreendido e, principalmente, utilizado em sua rotina diária. Além disso, devem ser apresentadas novas estratégias de investigação da temática sexualidade na deficiência intelectual como um todo - e também de avaliação das intervenções realizadas.

Este trabalho, especificamente, consistiu numa proposta de intervenção para pais sobre a sexualidade na deficiência intelectual e teve efeitos diversos dependendo da percepção de cada participante e de suas possibilidades. Procurou-se, no entanto, proporcionar oportunidades para o desenvolvimento do potencial de cada um como orientadores sexuais $\mathrm{e}$, mais do que isso, um questionamento global de si mesmos perante a questão da sexualidade.

\section{Referências}

Amaral, M. C. do. (2004). Sexualidade de deficiência mental: Impacto de um programa de orientação para famílias. Dissertação de Mestrado, Programa de Pós-Graduação em Educação Especial da Universidade Federal de São Carlos, São Carlos.

Assumpção Jr., F. B., \& Sprovieri, M. H. S. (2005). Deficiência mental: Sexualidade e família. Barueri: Manole.

Aunos, M., \& Feldman, M. A. (2002). Attitudes towards sexuality, sterilization and parenting rights of persons with intellectual disabilities. Journal of Applied Research in Intellectual Disabilities, 15(4), 285-296.

Ballan, M. (2001). Parents as sexuality educators for their children with developmental disabilities. SIECUS REPORT, 29(3), 14-19.

Bardin, L. (1977). Análise de conteúdo. São Paulo: Edições 70.

Bastos, O. M., \& Deslandes, S. F. (2005). Sexualidade e $\mathrm{o}$ adolescente com deficiência mental: Uma revisão bibliográfica. Ciência e saúde coletiva, 10(2), 1-13.

França Ribeiro, H. C. da. (2000). Sexualidade e escola: Encontros e desencontros. In E. J. Manzine (Org.). Educação especial: Temas atuais (pp. 85-114). Marília: UNESP/Marília Publicações.

Gherpelli, M. H. B. V. (1995). Diferente, mas não desigual: A sexualidade no deficiente mental. São Paulo: Gente. 
Giami, A. (2004). O anjo e a fera: Sexualidade, deficiência mental, instituição. São Paulo: Casa do Psicólogo.

Giulio, G. D. (2003). Sexuality and people living with physical or developmental disabilities: A review of key issues. The Canadian Journal of Human Sexuality, 12(1), 53-68.

Glat, R. (2005). Desarrollo psicosocial y sexualidad de jóvenes portadores de deficiencias. In M. E. Castilla, A. Frequest, \& M. A. Grzona, (Ed.). Educación especial: Vol.3 Otras miradas (pp. 5-14) Construir, desconstruir, reconstruir. Mendoza/Argentina: Facultad de Educación Elemental y Especial de la Universidad Nacional de Cuyo.

Glat, R., \& Freitas, R. C. de. (2002). Sexualidade e deficiência mental: Pesquisando, refletindo e debatendo sobre o tema. Rio de Janeiro: Sette Letras.

Glat, R., Nunes, L. R. D., Ferreira, J. R., \& Mendes, E. G. (1998). Pesquisa em educação especial na pósgraduação. Rio de Janeiro: Sette Letras.

Luengo, M. X. L. C, Virginia, T. D., Fuentes, M. E., Lobos L., Molina, R., \& Molina, T. (2000). Adolescentes discapacitados: Talleres de afectividad y sexualidad. Revista Chilena de Pediatria, 71(1).

Maia, A. C. B., \& Aranha, M. S. F. (2005). Relatos de professores sobre manifestações sexuais de alunos com deficiência no contexto escola. Interação em Psicologia, 9(1), 103-116.

Maia, A. C. B. (2006). Sexualidade e deficiências. São Paulo: Ed. UNESP.

Mccabe, M. P. (2005). Sex education programs for people with mental retardation. Mental Retardation, 31(6), 377-387.

Plunkett, S. W., Staceylee, L., Neal, R. A., \& Sanchez, M. G. (2002). An evaluation of a community-based sexuality education program for individuals with developmental disabilities. Eletronic Journal of Human Sexuality, 5. Recuperado em 20 nov. 2009 em http:/ / www.ejhs. org/volume5/plunkett/titlepage.html

Pueschel, S. M., \& Scola, P. S. (1988). Parent's perceptions of social and sexual functions in adolescents with Down's syndrome. Journal of Mental Deficiency Research, 32(3), 215-220.
Sampaio, I. E. (1995). Percepção de mães sobre a sexualidade de seus filhos deficientes mentais. Dissertação de Mestrado, Programa de PósGraduação em Educação Especial da Universidade Federal de São Carlos, São Carlos.

Schiavo, M. R. (2004). Manual de orientação sexual. São Paulo: O Nome da Rosa.

Werebe, M. J. G. (1998). Sexualidade, política e educação. Campinas: Autores Associados.

Recebido: 10/05/2010

Received: 05/10/2010

Aprovado: 03/09/2010

Approved: 09/03/2010 